\section{AINA NEWS}

\section{AINA Speaker Series 2015-16}

The Arctic Speakers Series is a monthly lecture series that is free and open to staff and students of the University of Calgary and the general public. The lectures typically take place on the third Wednesday of the month and begin at 4:00 p.m. They are followed by a reception at the offices of the Arctic Institute of North America on the 10th floor of the Earth Sciences Building, room 1040. The talks are recorded and uploaded to our YouTube Channel for widespread distribution.

The 2015-16 Speaker Series will commence on 23 September 2015 with the Northern Studies Training Program (NSTP) grant recipients presenting their research results. Speakers include Sarah Cole (Geography), Megan Goulding (Biology), Colleen Hughes (Anthropology and Archaeology), Laura Kapas (Biology), Kent Spiers (Anthropology and Archaeology), and Sarah St. Germain (Geography). On 21 October, Elena Favaro, a graduate student in Geography at the University of Calgary, will discuss the influence of rainfall influences on permafrost disturbances and sediment transport. Joel Berger, a senior conservation scientist with the Wildlife Conservation Society, will join us on 18 November to talk about how a changing climate is affecting Arctic wildlife. We take a break in the month of December and on 20 January 2016 we welcome Shari Gearheard of the National Snow and Ice Data Center in Boulder, Colorado, to discuss the interaction of people and sea ice in Arctic communities.

If you would like to receive email reminders about upcoming events, please contact us at arctic@ucalgary.ca to join the mailing list. For more information, visit: http:// arctic.ucalgary.ca/arctic-speaker-series-2015-16.

\section{ACUNS Student Conference}

AINA, the University of Calgary and the Association of Canadian Universities for Northern Studies (ACUNS) are pleased to announce that the "Due North: Next Generation Arctic Research and Leadership Student Conference" will be held at the University of Calgary on 5-8 November 2015.

The conference will provide young researchers the opportunity to exchange ideas, develop professional experience, and make national and international connections. The diverse sessions will include topics related to climate change, food security, natural resource development, Arctic policy, sustainable development, northern biodiversity and conservation, education, and circumpolar health.

Abstract submission and registration are ongoing. For more information, please visit the conference website: http://arctic.ucalgary.ca/acuns-2015-student-conference or email the conference organizers at acuns15@ucalgary.ca.

\section{AuroralZone}

On 13 August 2015, the Department of Physics and Astronomy at the University of Calgary, in collaboration with the Arctic Institute of North America, the Canadian Space Agency, Aurorasaurus, and AuroraMAX, launched a citizen science website to recruit the public in aurora classification. The AuroralZone initiative teaches learners of all ages the science behind the aurora-how the aurora is created and what it can tell us about space weather. Using this information, participants can scroll through real images of the aurora taken from the Canadian North and identify its different forms. This information is relayed directly back to scientists, who will use it to study the physics of the aurora and the near-earth environment.

The AuroralZone website was launched at the Telus Spark Adults Only Night in Calgary, Alberta. Participants competed with friends and peers to see who could correctly classify the most images on dueling touch-screen tables. Winners were awarded exclusive AuroralZone gear.

To learn more about the project and to try out your aurora classification skills, please visit www.auroralzone. com or http://arctic.ucalgary.ca/northern-skies.

\section{Beakerhead}

September is Beakerhead month in Calgary, and the Arctic Institute of North America is celebrating this festival of arts, science, and engineering on 18 September 2015 at the Rothney Astrophysical Observatory. John MacDonald, author of The Arctic Sky: Inuit Astronomy, Star Lore, and Legend, recounts Inuit legends of the Arctic Universe, and Eric Donovan, University of Calgary Associate Professor in the Department of Physics and Astronomy, discusses leading-edge auroral research. Learn how you can get involved by classifying images of the aurora at www.auroralzone. com. The program runs from 7:30 to 9:30 p.m. and tickets are $\$ 10 /$ person or $\$ 20 /$ car. Stay late to explore the night sky through the lens of a telescope.

\section{PoLAR Voices}

Coming this fall: the second installment of the PoLAR Voices podcast. The podcast has been revitalized this season to showcase the latest in climate change research from top researchers in the polar regions and to highlight personal stories of change from people living and working in the Arctic. Watch the PoLAR Voices page at http:// thepolarhub.org for updates and new episodes. PoLAR Voices is produced by the University of Alaska Museum of the North, in partnership with the University of Alaska Fairbanks, the International Arctic Research Center, and the Arctic Institute of North America, as part of the Polar Learning and Responding Climate Change Education Partnership. 


\section{ASTIS Reaches 81000 Records}

The Arctic Science and Technology Information System (ASTIS) now contains 81000 records describing 63500 publications and 17500 research projects about northern Canada and the circumpolar Arctic. ASTIS covers all subjects including the earth sciences, the biological and health sciences, engineering and technology, the social sciences, traditional knowledge, history, and literature. The database includes both peer-reviewed and grey literature and covers the three territories, the northern parts of seven provinces, and the adjacent marine areas. ASTIS records contain abstracts, detailed subject and geographic indexing terms, and links to 23000 online publications. ASTIS also maintains subset databases that provide selected records and background information for specific regions, subjects, or projects. A project of the Arctic Institute of North America since 1978, ASTIS is available for free from a bilingual website at www.aina.ucalgary.ca/astis.

Interested in supporting this public resource? Contact Shannon Vossepoel at astis@ucalgary.ca for more information.

\section{ASTIS supports ORCID Identifiers}

The Open Researcher and Contributor ID (ORCID) provides a unique identification number for individuals, enabling ASTIS to ensure that all publications by an author are attributed to him or her, no matter how many forms of that author's name appear in our database. When viewing a Full Record in ASTIS, authors with ORCIDs are shown in bold. If you click on a bold personal author name, ASTIS will search by ORCID identifier and all records by that person will be found. If you click on a non-bold personal author name, ASTIS will search only for records with that exact form of the name and will miss any alternative forms or names. ASTIS currently has ORCID identifiers for 335 Canadian Arctic researchers in our database. If you have records in ASTIS and would like all of them to be retrieved when your name is clicked, please obtain an ORCID identifier (www.orcid.org) and send it to astis@ucalgary.ca.

\section{ASTIS Subset Databases Expand}

The Nunavik Bibliography (www.aina.ucalgary.ca/ nunavik) now describes 7700 publications about Quebec north of $55^{\circ}$ and some adjacent regions. ASTIS information analysts traveled to Kuujjuak in July and added many more publications from the Nunavik Research Centre Library to the database. ASTIS would like to thank Makivik Corporation for providing the funding to support this important work.

The NCP Publications Database (www.aina.ucalgary. $\mathrm{ca} / \mathrm{ncp}$ ) has grown significantly in the past year and now describes more than 3200 publications from the Northern Contaminants Program. Publications include, but are not limited to, NCP Secretariat publications, AMAP and CACAR reports, books, journal articles, theses, and posters. Now also a repository for NCP publications, the database includes items not otherwise available online. ASTIS is pleased to work with the Northern Contaminants Program to provide this searchable archive of their publications.

\section{ArcticConnect Sensor Web Expands}

Interested in sensor information coming out of the Canadian Arctic? ArcticConnect's Sensor Web (http://sensorweb.arcticconnect.org) now contains sensor information for more than 160 research stations across the pan-Arctic including the Arctic Institute's own Kluane Lake Research Station. To find out more about ArcticConnect, visit www. arcticconnect.org. 